\title{
La Iglesia y la Nueva Evangelización ${ }^{1}$
}

\author{
A lgreja e a nova evangelização
}

\author{
The church and the new evangelization
}

Olga Consuelo Vélez Caro

\section{Resumen}

Con la llegada del Obispo de Roma, Francisco, asistimos a un nuevo tiempo en la iglesia que estamos llamando de "primavera eclesial”. Pero ¿por qué hablar de primavera cuando hace relativamente poco hablábamos de "invierno eclesial"? Hacer un recorrido histórico por los modelos eclesiales trazados desde Vaticano II, pasando por las Conferencias Episcopales Latinoamericanas y caribeñas y delineando el modelo que perfila las palabras y obras de Francisco, puede ayudarnos a comprender este nuevo momento y a formular los desafíos actuales para que esa primavera se quede, haciendo posible una Iglesia en seguimiento de Jesús, del lado de los pobres y viviendo una nueva evangelización capaz de abrir caminos de vida para todos y todas.

Palabras claves: Iglesia pobre; Evangelización; Seguimiento; Dimensión social.

\section{Abstract}

With the arrival of the Bishop of Rome, Francisco, we are seeing a new time for the Church what we call: "spring Church". But, Why We are talking of "spring Church" when until recently we talked of "winter Church"? Take

\footnotetext{
${ }^{1}$ Las ideas centrales de esta publicación fueron presentadas por la autora, como Ponencia, en el Segundo Congreso de Teología para Laicos, Barranquilla, Colombia, 01-11-2014.
} 
a historical journey through the ecclesial models drawn from Vatican II and the Latin American and Caribbean Episcopal Conferences and the model that Francisco's words and attitudes is outlining, can help us understand this new time and to formulate the current challenges for that spring to stay, making possible a church following to Jesus, on the side of the poor people and living a new evangelization capable of opening paths of life for all.

Keywords: Poor Church; Evangelism; follow up; Social dimension.

\section{Resumo}

Com a chegada do Bispo de Roma, Francisco, nós estamos assistindo a um novo tempo na Igreja que estamos chamando de "primavera eclesial". Mas, por que falar de primavera quando há relativamente pouco nós falávamos de "inverno eclesial"? Fazer um percurso histórico pelos modelos eclesiais traçados desde Vaticano II, passando pelas Conferencias Episcopais Latinoamericanas e caribenhas e delineando o modelo que orienta as palavras e obras de Francisco, pode nos ajudar a compreender este novo momento e a formular os desafios atuais para que essa primavera eclesial fique, tornando possível uma igreja em seguimento de Jesus, do lado dos pobres e vivendo uma nova evangelização capaz de abrir caminhos de vida para todos e todas.

Palavras-chave: Igreja pobre; Evangelização; Seguimento; Dimensão social.

\section{Introducción}

La Exhortación Apostólica Evangelii Gaudium (2013) del Papa Francisco señala con claridad el tema que pretendemos reflexionar aqui: El numeral 17, dice así: "Aquí he optado por proponer algunas líneas que puedan alentar y orientar en toda la Iglesia una nueva etapa evangelizadora, llena de fervor y dinamismo. Dentro de este marco y con base en la doctrina de la Constitución dogmática Lumen Gentium, decidí detenerme en las siguientes cuestiones: (1) La reforma de la Iglesia en salida misionera (2) Las tentaciones de los agentes pastorales (3) La Iglesia entendida como la totalidad del Pueblo de Dios que evangeliza (4) La homilía y su preparación (5) La inclusión social de los pobres (6) La paz y el diálogo social (7) Las motivaciones espirituales 
para la tarea misionera. El Papa señala que se detuvo en estos asuntos no para ofrecer un tratado sobre los mismos, sino para "mostrar la importante incidencia práctica de esos asuntos en la tarea actual de la Iglesia. Todos ellos ayudan a perfilar un determinado estilo evangelizador que invito a asumir en cualquier actividad que se realice" (EG 18).

Siguiendo este camino trazado por el Papa queremos detenernos en este artículo en cuatro aspectos concretos. En primer lugar, describir la transformación eclesiológica que supuso Vaticano II, para captar la novedad que este concilio implicó y los caminos que se han recorrido en ese sentido. En segundo lugar, mirar nuestra Iglesia latinoamericana y caribeña que en sus Conferencias Episcopales ha buscado plasmar la novedad del Concilio, posibilitando la transformación de las iglesias locales. En tercer lugar, haremos un quiebre a ese desarrollo magisterial que parece ir por buen camino pero que no ha producido los frutos esperados. Nos preguntamos entonces, ¿Qué pasa con la vitalidad de la Iglesia? ¿qué llevó a que se hablara en estas últimas décadas de un invierno eclesial? Finalmente, retomaremos los caminos trazados por el Papa Francisco - como comenzamos señalando - para ver la potencialidad que tienen, los riesgos que conllevan y las esperanzas que traen, de cara a impulsar una Iglesia en camino, una nueva primavera, capaz de propiciar una Nueva Evangelización que llegue a todos y todas y mantenga encendido el discipulado misionero al que estamos llamados.

\section{Un nuevo modelo eclesial: Una Iglesia Pueblo de Dios, sacramento de comunión y salvación}

Mucho se ha escrito sobre el modelo eclesial trazado por Vaticano II, especialmente al conmemorar sus 50 años de celebración ${ }^{2}$. No es por tanto, nuestro objetivo, presentar una reflexión completa y exhaustiva de este legado sino señalar algunos aspectos fundamentales para comprender este caminar eclesial y seguirlo impulsando hacia una Nueva evangelización profética, audaz y renovada.

\footnotetext{
${ }^{2}$ CODINA, ZUBIRÍA, COMBLIN, BALDUINO. "A 50 años del Vaticano II: verdaderas luces y urgentes desafíos”. Revista Alternativas 41 (2011); PONENTES “Semana Teológica Amerindia". A los 50 años del Concilio Vaticano II. Compendio de Ponencias presentadas en la "Semana Teológica". Cochabamba: Grupo Editoral "Kipus", 2011, pp. 33-48. Disponible en: http://amerindiaenlared.org/noticia/176/a-los-50-anos-del-concilio-vaticano-ii/. Consultado el 12 de Octubre de 2014.
} 
Vaticano II se reconoce como un "Nuevo Pentecostés", un momento de aggiornamiento profundo, una renovación necesaria y urgente. Más que un momento puntual, se puede considerar como un acontecimiento preparado en las décadas anteriores - tanto por los cambios propiciados por la modernidad como por el desarrollo teológico de los años precedentes - que desencadenó una fuerza de vida que transformó, efectivamente, la praxis eclesial de la Iglesia universal, viéndose por eso mismo, expuesto a críticas, incomprensiones, equivocaciones pero también a fidelidades - a toda prueba - que permiten recoger hoy, frutos invaluables. Con otras palabras, Vaticano II podría considerarse "una mirada irreversible (...) las anclas han sido elevadas, no importa si en el mar todavía existen corrientes resistentes o remolinos peligrosos. Ella sigue en marcha."3

Vaticano II se ha considerado un concilio eclesiológico porque todos sus documentos, desde sus temas particulares, configuran un nuevo modo de ser Iglesia o nuevo paradigma eclesiológico. De una Iglesia preocupada, casi exclusivamente, por definirse a sí misma y afirmar su ser y su esencia, se pasó a una Iglesia capaz de valorar la actividad humana (GS 3), respetar su autonomía y valorar sus logros. Una iglesia capaz de dar nombre a las realidades del mundo y comprender que sólo desde ellas podía realizar su tarea evangelizadora. La economía, la política, la educación, lo social, los problemas humanos, entre otros aspectos, comenzaron a ser objeto de reflexión mediante diferentes mediaciones sin las cuales el reino de Dios no podría visibilizarse y concretarse ${ }^{4}$.

La comprensión de la revelación como aconteciendo en la historia, mediante hechos y palabras, que han de ser interpretados (DV 2) cambió el horizonte epistemológico de la teología y la pastoral. Esa encarnación de la revelación dio como fruto una teología histórica y una pastoral que parte del "ver" porque ahí se manifiesta el actuar de Dios, su palabra hecha historia. No menos importante fue la reforma litúrgica porque "como cara pública de la Iglesia" fue la que más expresó los cambios propiciados por Vaticano II. En la Constitución Sacrosanctum Concilium se marcó la centralidad cristológica de

\footnotetext{
${ }^{3}$ MADERA, I. "Una mirada irreversible". Revista Theologica Xaveriana 149 (2003), pp. 459-472, 461.

${ }^{4}$ VÉLEZ, C. “A 50 años del Vaticano II: verdaderas luces y urgentes desafíos”. Revista Alternativas 41 (2011), pp. 89-100, 90-91.

${ }^{5}$ ALBARRACÍN, T. "Perspectivas de la reforma litúrgica". Revista Theologica Xaveriana 149 (2003), pp. 513-521, 514.
} 
la liturgia (5), la importancia de la formación y la participación activa de los sacerdotes y fieles en ella (14-19), su adaptación a la mentalidad y tradiciones de los pueblos (37-40), la importancia del signo y la necesidad de simplificarlo para que el Pueblo de Dios pudiera entenderlo y participara activamente en la celebración eucarística (47-58). Muy importantes fueron también el Decreto sobre el ecumenismo y las Declaraciones sobre la libertad religiosa y las relaciones de la Iglesia con las religiones no cristianas. Con estos documentos la Iglesia se abrió al diálogo y a la construcción común de la sociedad en la que había de ser signo del reino de Dios.

Precisamente este último aspecto es lo que la Constitución Lumen Gentium desarrolla, definiendo la Iglesia como Sacramento del reino, recordando que "nuestro Señor Jesús dio comienzo a su Iglesia predicando la buena nueva, es decir, la llegada del Reino de Dios (...) Por eso la Iglesia, enriquecida con los dones de su Fundador (...) recibe la misión de anunciar el Reino de Cristo y de Dios, de establecerlo entre todas las gentes, y constituye en la tierra el germen y el principio de este Reino (LG 5). Y en este sentido tal vez el cambio más importante que la LG propició, se manifiesta en la misma estructura del texto que pone como puerta de entrada el "Misterio de la Iglesia" (1-8), es decir el don de Dios del que la Iglesia ha de ser sacramento. En un segundo lugar, la Iglesia se define como "Pueblo de Dios", manifestando, por una parte, esa continuidad con el pueblo elegido pero, a su vez, mostrando la "alianza nueva" que supone el constituirse pueblo en Cristo, donde Él es la cabeza del cuerpo y todos los demás somos su cuerpo, partícipes plenos de la triple función sacerdotal, profética y real del mismo Cristo y llamados todos a participar de la actividad misionera de la Iglesia (9-17). Este modelo de Iglesia surge en contraste con el modelo "Sociedad perfecta" que se había configurado en los siglos precedentes, más centrado en lo legal o jurídico y preocupado por establecerse en la sociedad, opacando su misión de ser sacramento de salvación, pueblo de Dios, congregado en su nombre.

En la LG, una vez consolidados los elementos esenciales - el don de Dios o el misterio de la Iglesia y la dignidad e igualdad fundamental de todos los miembros en la Iglesia -, se pasa a presentar los diferentes ministerios y carismas, los estados de vida, la llamada universal a la santidad para todo el pueblo de Dios. De estos capítulos muchas cosas son importantes pero destaquemos tres: la colegialidad episcopal que articula mejor el primado petrino con la potestad de cada Obispo en su diócesis, la plenitud de la vida laical y la renovación de la vida consagrada, mostrando así, la pluralidad del 
Pueblo de Dios pero su íntima relación para una vocación y misión común. Buscando resumir en algunas frases todo el cambio eclesial que se produjo con Vaticano II, podríamos decir que este Concilio propició el paso:

- De la Iglesia de cristiandad, típica del Segundo milenio, centrada en el poder y la jerarquía, a la Iglesia del Tercer Milenio, que recupera la eclesiología de comunión típica del Primer milenio y al mismo tiempo se abre a los nuevos signos de los tiempos.

- De una eclesiología centrada en sí misma, a una Iglesia orientada al Reino.

- De una Iglesia sociedad perfecta a una Iglesia misterio, fundamentada en la Trinidad.

- De una iglesia centralista a una iglesia corresponsable y sinodal que respeta las Iglesias locales.

- De una Iglesia identificada con la jerarquía a una Iglesia toda ella Pueblo de Dios con diversos carismas.

- De una iglesia triunfalista, a una iglesia peregrina, santa y pecadora.

- De una Iglesia señora y dominadora, madre y maestra universal, a una Iglesia servidora de todos y, en especial, de los más pobres.

- De una iglesia comprometida con el poder, a una iglesia solidaria con los pobres y marginados.

- De una Iglesia arca de la salvación a una Iglesia Sacramento de salvación, en diálogo con las otras Iglesias y las otras religiones de la humanidad, reconociendo la libertad religiosa ${ }^{6}$.

Muchos otros aspectos podríamos resumir aquí pero conviene más bien detenernos en lo que ese concilio significó en nuestra realidad latinoamericana y caribeña y cuál ha sido ese caminar en estos cincuenta años.

${ }^{6}$ IRIARTE, G. "Bodas de Oro del Vaticano II", In: PONENTES "Semana Teológica Amerindia". A los 50 años del Concilio Vaticano II. Compendio de Ponencias presentadas en la "Semana Teológica". Cochabamba: Grupo Editoral "Kipus", 2011, pp. 33-48, 35. Disponible en: http://amerindiaenlared.org/noticia/176/a-los-50-anos-del-concilio-vaticano-ii/. Consultado el 12 de Octubre de 2014; CODINA, V. "Del Vaticano II... a ¿Jerusalén II?". Revista Alternativas 41 (2011), pp. 65-74, 65-66. 


\section{Caminos trazados por la Iglesia latinoamericana y caribeña: el compromiso con la realidad y el discipulado misionero}

Como ya hemos anotado, Vaticano II tuvo un impacto universal y la Iglesia ya no es la misma después de ese acontecimiento. Y en América Latina podemos comprobar una recepción creativa de esas líneas trazadas y una apertura pastoral y teológica que ya forman parte del patrimonio universal de la Iglesia y, con sus luces y desafíos, han de incorporarse al desarrollo eclesial y no pueden dejarse de lado a la hora de pensar la renovación eclesial.

Las Conferencias Generales del Episcopado Latinoamericano y Caribeño marcan el caminar latinoamericano que en esta sección hemos resumido, demasiado sucintamente, en el compromiso con la realidad y el discipulado misionero. El primer aspecto lo sitúo más en las Conferencias de Medellín, Puebla y Santo Domingo y, el último, en la Conferencia de Aparecida mucho más próxima a nuestra vivencia.

En Medellín (1968) los temas tratados y compilados en sus conclusiones dan idea clara de un deseo sincero de mirar la realidad y responder a ella. El primer documento referido a la "Promoción humana" aborda el tema de la Justicia, fundamentándola doctrinalmente y señalando sus proyecciones pastorales. El segundo documento sobre la "Paz" reconoce las tensiones que se vivían en esos tiempos en América Latina y muestra una clara postura eclesial de denuncia de la injusticia para la construcción de la paz. Los temas de la "Familia y Democracia", "Educación", "Jóvenes", buscan responder a la manera como la realidad socioeconómica y cultural afecta estas realidades y la urgencia de la Iglesia de apoyar estos aspectos y fortalecerlos en esos momentos de cambio. Mirando la realidad intraeclesial el documento aborda la pastoral popular, la de las élites, la catequesis, la liturgia, los movimientos de laicos, los sacerdotes, los religiosos y la formación del clero. Como se puede ver, la renovación eclesial atraviesa la visión de mundo, de Iglesia, de misión. Pero tal vez el numeral más significativo fue el de "Pobreza de la Iglesia" en el que reconociendo el "sordo clamor que brota de millones de personas, pidiendo a sus pastores una liberación que no les llega de ninguna parte e identificando a la Iglesia más del lado de la riqueza que de los pobres, se hace un llamado muy fuerte a la pobreza de la Iglesia como "signo de un valor inestimable del pobre a los ojos de Dios y compromiso de solidaridad con los que sufren". El documento de Medellín aborda además la Pastoral de conjunto y los Medios de comunicación. No sobraría que se volviera a 
la lectura de este documento, con los ojos de quien quiere contemplar como Dios acontece en su pueblo y hace surgir tan valiosas propuestas y audaces compromisos.

El documento de Puebla (1979) fue tal vez uno de los más estudiados y llevados a la práctica por todo el Pueblo de Dios. Es aquella época de la vitalidad de una Iglesia pobre, de una liturgia rica en solidaridad y compromiso social y una teología que acompañó ese caminar, la teología de la liberación que, tantos y tan valiosos frutos ha dado, a la teología universal. Es tiempo también de muchas tensiones y conflictos, de miedos y vueltas atrás, de errores y enfrentamientos, que produjeron rupturas, condenas y mutuas descalificaciones. Pero lo importante de rescatar aquí, es la voz profética de una Iglesia capaz de mirar la realidad, iluminarla con la luz de la fe y proponer acciones pastorales que respondieran a dicha situación. La opción preferencial por los pobres es clara y decisiva: "Volvemos a tomar, con renovada esperanza en la fuerza vivificante del Espíritu, la posición de la II Conferencia General que hizo una clara y profética opción preferencial y solidaria por los pobres, no obstante las desviaciones e interpretaciones con que algunos desvirtuaron el espíritu de Medellín, el desconocimiento y aún la hostilidad de otros. Afirmamos la necesidad de conversión de toda la Iglesia para una opción preferencial por los pobres, con miras a su liberación integral" (1134). No menos importante es la opción que se hace por los jóvenes y, en general, todo el espíritu del documento que tiene sabor a evangelio, a Jesús, a los destinatarios privilegiados del reino: los pobres.

El documento de Santo Domingo (1992) a pesar de las dificultades para la misma realización de la Conferencia y las tensiones por el método (se dio un temor legítimo de "sociologizar" la religión y no enfatizar suficientemente la doctrina), dio como fruto una valiosa reflexión sobre la Nueva Evangelización, la promoción humana y la cultura, como el título del documento lo señala. Con este documento se dieron pasos para la inculturación de la fe y la necesidad de una evangelización capaz de asumir los desafíos culturales y responder a la promoción integral de todos los seres humanos. La articulación entre evangelización y promoción humana, va en continuidad con el tan valorado documento de Pablo VI, Evangelli Nuntiandi (1975), señalando la intrínseca relación entre evangelización y promoción humana porque "nuestra fe en el Dios de Jesucristo y el amor a los hermanos debe traducirse en obras concretas" (SD 160). El abordaje de temas tan actuales hoy como los Derechos humanos, la ecología, la tierra, el empobrecimiento y la solidaridad, el trabajo, 
la movilidad humana, el orden democrático y económico y la integración latinoamericana, señalados como signos de los tiempos, aportaron profundas y actuales reflexiones, que la evangelización de la Iglesia no puede dejar de lado en su misión.

Pero tal vez la Conferencia de Aparecida (2007) por la cercanía histórica que representa, es el documento que ha buscado inspirar el caminar de la Iglesia latinoamericana en estos tiempos y su aporte se condensa en el mismo lema de la conferencia y la propuesta de una misión continental como medio y forma de implementarla. "Discípulos misioneros para que nuestros pueblos en Él tengan vida", nos habla de una Iglesia misionera. Es decir, no es que la Iglesia tenga una misión, es que ella misma es misión. Este lema destaca dos aspectos irrenunciables de esa misión: el discipulado misionero - como dos caras de la misma moneda -, y la misión de dar vida y vida en abundancia (Jn 10, 10).

Es de destacar la referencia al método latinoamericano que el documento hace en el n.19: "Muchas voces venidas de todo el Continente ofrecieron aportes y sugerencias en tal sentido, afirmando que este método ha colaborado a vivir más intensamente nuestra vocación y misión en la Iglesia, ha enriquecido el trabajo teológico y pastoral, y en general ha motivado a asumir nuestras responsabilidades ante las situaciones concretas de nuestro continente. Este método nos permite articular, de modo sistemático, la perspectiva creyente de ver la realidad; la asunción de criterios que provienen de la fe y de la razón para su discernimiento y valoración con sentido crítico; y, en consecuencia, la proyección del actuar como discípulos misioneros de Jesucristo. La adhesión creyente, gozosa y confiada en Dios Padre, Hijo y Espíritu Santo y la inserción eclesial, son presupuestos indispensables que garantizan la eficacia de este método". De esa manera se consolida ese compromiso con la realidad que hace que la pobreza e injusticia estructural tome el primer lugar en los esfuerzos evangelizadores.

Mucho se podría destacar de este acontecimiento de Aparecida pero basta señalar algunos aspectos muy concretos. El reconocimiento del "cambio de época" (DA 44) que se está viviendo, lo cual es supremamente importante para no caer en cambios superficiales sino en lo que el mismo documento llama una "Conversión Pastoral y misionera". Esta conversión ha de ser tarea de todos "Obispos, presbíteros, diáconos permanentes, consagrados y consagradas, laicos y laicas" y supone un "escuchar con atención y discernir "lo que el Espíritu está diciendo a las Iglesias' (Ap 2,29), a través de los signos de los tiempos en los que Dios se manifiesta" (DA 366). El documento señala que 
los Pastores han de promover una pastoral de comunión y participación donde haya apertura, diálogo y disponibilidad para promover la corresponsabilidad y participación efectiva de todos los fieles en la vida de las comunidades cristianas (DA 368). En este mismo sentido, Aparecida invita a pasar de "una pastoral de conservación a una pastoral decididamente misionera" (DA 370).

Muy importante es el énfasis que la V Conferencia da al "Itinerario formativo de los discípulos misioneros" (DA Cap. 6) y la continuidad con las otras Conferencias al reafirmar la "Opción preferencial por los pobres". Aquí cabe destacar que en el Discurso Inaugural el Papa Benedicto XVI (DI n.3; DA 392), dijo que "la opción preferencial por los pobres está implícita en la fe cristológica" y esta afirmación marcó el desarrollo de la misma Conferencia y su concreción tan decidida por una Iglesia que en el despliegue de su ser misionero no puede menos que partir de los rostros de los más pobres y excluidos, de todos aquellos por los que Dios se inclina preferentemente. Esta opción por los últimos, no se basa en que ellos sean buenos, sino porque son pobres y necesitan más que ninguno de su primera misericordia. Aparecida ratifica y potencia "la opción del amor preferencial por los pobres hecha en las Conferencias anteriores" y añade que el hecho de "que sea preferencial implica que debe atravesar todas nuestras estructuras y prioridades pastorales. La Iglesia latinoamericana está llamada a ser sacramento de amor, solidaridad y justicia entre nuestros pueblos" (DA 396).

Con el recorrido dado hasta aquí de manera muy breve pero queriendo señalar la experiencia eclesial que se ha vivido en la Iglesia latinoamericana y caribeña, podemos concluir que el modelo de Iglesia comunión señalado en Vaticano II, se ha seguido impulsando en el continente, y Aparecida invita a concretarla en todas las estructuras eclesiales desplegando un espíritu misionero que busque responder a la urgencia de una evangelización comprometida con realidad que vivimos con sus múltiples y complejos desafíos.

\section{Pero... ¿Qué nos llevó a hablar de "invierno eclesial"?}

Todo este camino en línea de continuidad, como lo hemos señalado, no ha gozado de la misma vitalidad allí descrita, ni ha conseguido el despliegue

\footnotetext{
${ }^{7}$ Expresión atribuida a Karl Rahner. Otras expresiones en el mismo sentido: "Involución eclesial" (revista Concilium), "Restauración" (GC Zízola), "Vuelta a la gran disciplina" (J.B. Libanio), "Noche oscura" (J.I. González Faus). CODINA, V. Sentirse Iglesia en el invierno eclesial, Barcelona: Cuadernos Cristianisme e Justícia, 2006, 6.
} 
que podríamos suponer. ¿Cuál es la causa de que se estuviera hablando en la última década de "invierno eclesial"?

Podemos señalar causas intraeclesiales y extraeclesiales ${ }^{8}$. En las primeras se sitúa un miedo que parece haberse apoderado de la Iglesia ante los cambios y una vuelta, "no a los orígenes" como se había señalado en Vaticano II, sino al fundamentalismo, al anquilosamiento, al tradicionalismo (diferente de la "Tradición" -expresión de los fundamentos, del origen, muy distinto de un apego a lo accesorio, a lo provisional a lo que llamamos "tradicionalismo"). Poco a poco se fue reforzando un centralismo eclesial, debilitando las Iglesias particulares, una actitud de sospecha frente a cualquier propuesta teológica o pastoral, poniendo freno a las voces proféticas, una fijación frente a la "ortodoxia" de algunos temas de moral descuidando tantos otros aspectos vitales de la vida cristiana, la falta de diálogo con el mundo de la ciencia, la búsqueda de poder y la seguridad eclesial, el poco protagonismo de los laicos $\mathrm{y}$, especialmente, de la mujer, los pocos espacios para el diálogo ecuménico e interreligioso, junto con el anti testimonio de clérigos con el tema de la pederastía y la alianza que muchas veces los espacios oficiales de la Iglesia han tenido con gobiernos más dictatoriales y con los dueños del poder en las diferentes realidades. En otras palabras, las estructuras eclesiales no están respondiendo eficazmente a las situaciones actuales y, en lugar de atraer con el anuncio de la Buena Noticia del Reino, cada vez pareciera que más personas se alejan de la institución y viven al margen de toda referencia eclesial. No son tiempos de ateísmo, por el contrario, son tiempos de variadas búsquedas espirituales -sean de signo confesional o no- pero, sin duda, son tiempos de crisis de institucionalidad.

Pero también las causas externas de los cambios socio culturales que estamos viviendo han debilitado la presencia eclesial. Son tantos y tan variados que la iglesia se encuentra "desconcertada ante los avances de la técnica, la globalización, la mentalidad posmoderna". La pluralidad cultural y religiosa exige repensar los fundamentos antropológicos y teológicos de la concepción de ser humano, de identidad sexual, del valor de todas las religiones y su papel en la salvación, entre muchos otros aspectos.

A nivel de nuestro continente latinoamericano la pregunta es ¿qué pasó después de Aparecida? ¿se ha desplegado la actitud misionera que allí se

\footnotetext{
${ }^{8}$ Seguimos los aportes de CODINA, V. "Sentirse Iglesia en el invierno eclesial".

${ }^{9}$ CODINA, V. "Sentirse Iglesia en el invierno eclesial", 7.
} 
proclamó? Puede decirse que se han hecho esfuerzos en muchas partes del continente $y$, sin embargo, los frutos no han sido los esperados. La Iglesia sigue perpleja, sin saber cómo salir al mundo. Tiene la tentación de replegarse en los que "permanecen en la Iglesia", fortaleciendo sus pastorales y reforzando sus seguridades, mirando el mundo exterior como un enemigo que sigue robando poder a la iglesia y valores a la sociedad y, contentándose tal vez con un discurso de condena frente a lo distinto y una incapacidad cada vez mayor de entenderlo.

Pero hoy renace una esperanza. La elección del Papa Francisco, ha traído aires nuevos en varios sentidos. En primer lugar, él es consciente de la necesaria reforma de la Iglesia. Por eso nombró una comisión de 8 Cardenales con los que está trabajando para repensar la estructura eclesial y propiciar cambios ${ }^{10}$. En segundo lugar, ha afrontado con valentía los problemas, tal vez más dolorosos y escandalosos de la jerarquía, como son las cuestiones económicas (Banco Vaticano), la pederastía, etc. Pero, en tercer lugar, lo más importante: antes de dar discursos, él como persona ha sido testimonio de un estilo distinto de ser Iglesia: una iglesia sencilla, del lado de los pobres, con una capacidad de misericordia y acogida. Y esos pequeños pero, significativos gestos, han sembrado esperanza dentro de la Iglesia - que sentía el peso del "Invierno eclesial" - aunque también, hay que reconocer, que ha creado desconcierto en los que están apegados a sus seguridades y no están dispuestos a cambiar nada-. Queremos, por tanto, retomar los caminos trazados por Francisco para iluminar la tarea que tenemos entre manos, en este momento de "Nueva Evangelización".

\section{Hacia un nuevo modelo eclesial: Siguiendo los caminos trazados por el Obispo de Roma}

Acabamos de señalar que si algo ha despertado la esperanza en la Iglesia, han sido los "signos" realizados por Francisco desde el inicio de su Pontificado (13-03-2013). Y la novedad o el respaldo que ha tenido su primera Exhortación Apostólica, la "Evangelii Gaudium" (21-11-2013) ${ }^{11}$ proviene de que, de alguna manera, ha puesto por escrito como documento de su magisterio, lo que antes ha practicado en su propia persona. Por eso, al aproximarnos a esa exhortación

\footnotetext{
${ }^{10}$ Posiblemente cuando este artículo sea publicado, el Papa ya habrá anunciado algunos de los cambios propuestos por esta Comisión de Cardenales.

${ }^{11}$ Sabemos que el primer escrito fue la Encíclica Lumen Fidei, escrita en colaboración con Benedicto XVI (5-07-2013). Por eso la primera escrita solo por él, es la Evangelii Gaudium.
} 
podemos entender los caminos que está señalando para la actividad misionera de la Iglesia y disponernos a secundarlos. Es el propósito de este apartado.

¿Por dónde ha de caminar la Iglesia en esta "Nueva Evangelización”? El Papa comienza su Exhortación señalando que esta "nueva etapa evangelizadora ha de estar marcada por la alegría del Evangelio" (1). He aquí la primera clave: la alegría ha de ser la actitud que nos tiene que acompañar y el fruto que debemos procurar. Una evangelización atravesada por la alegría. Esta actitud nos remite a la bella parábola del tesoro escondido (Mt 13, 44-45) donde aquel hombre "por la alegría que le da el encuentro del tesoro", va vende todo lo que tiene y compra aquel campo. Quien no descubre la alegría del evangelio, no puede tener la fuerza para dejar todo lo demás y dedicarse en exclusiva a esta tarea.

La misericordia divina es otra actitud que no puede faltar en la evangelización. En la introducción de la EG, Francisco comienza recordando que "Dios no se cansa nunca de perdonar, somos nosotros los que nos cansamos de acudir a su misericordia" (EG 3). Más adelante, al referirse a la necesaria transformación de la iglesia, sitúa la misión en "el deseo inagotable de brindar misericordia, fruto de haber experimentado la infinita misericordia del Padre" (EG 24). Afirma, citando a Santo Tomás, que "la misericordia es la mayor de todas las virtudes" (EG 37) y reconoce que los preceptos eclesiales que han sido muy eficaces en otras épocas, pueden hacer pesada la vida de los fieles lo que llevaría a convertir la religión en una esclavitud, cuando la misericordia de Dios quiso que fuera libre" (EG 43).

El Papa no pretende disminuir el ideal evangélico pero si "acompañar con misericordia y paciencia las etapas de crecimiento de las personas" y recuerda a los sacerdotes que "el confesionario no es una sala de torturas sino el lugar de la misericordia del Señor" (EG 44). Más aún, la Iglesia tiene que ser "el lugar de la misericordia gratuita, donde todo el mundo pueda sentirse acogido, amado, perdonado y alentado a vivir según la vida buena del Evangelio" (EG 114). Las bienaventuranzas empujan a este amor misericordioso "Sed misericordiosos como el Padre celestial es misericordioso" porque el hermano es la prolongación de la Encarnación de Jesús para nosotros (EG 179). La misericordia con los demás nos permite salir triunfantes en el juicio divino porque el que tuvo misericordia, obtendrá misericordia (EG 193). Precisamente porque el evangelio es un evangelio de la misericordia, la Iglesia escucha el clamor por la justicia y quiere responder a él con todas sus fuerzas (EG 188). Esta actitud lleva a mantenerse en continuidad con la Sagrada Escritura que considera la misericordia con los pobres fuente de santidad y fidelidad al Dios que anuncia (EG 193). 
Para el Papa el evangelio de la misericordia con el pobre es "tan claro, directo, simple y elocuente" que pide "no complicar lo que es tan simple" ni "oscurecer lo que es tan claro" y advierte de los peligros que tienen los que están preocupados sólo por la ortodoxia sin caer en cuenta de que, muchas veces, se vuelven cómplices de injusticias intolerables y de regímenes políticos que mantienen esas situaciones, por perder ese "camino luminoso de vida y sabiduría" (EG 194). En efecto "a los pobres Dios les otorga su primera misericordia" y por eso "la opción preferencial por los pobres" (EG 198) forma parte de la experiencia cristiana.

Como tercer elemento y muy en consonancia con el caminar de la Iglesia latinoamericana - de la que el Papa es parte y fue protagonista en la V Conferencia - es el señalar los destinatarios privilegiados de la evangelización: "los pobres". Aclara que "la opción por los pobres es una categoría teológica antes que cultural, sociológica, política o filosófica" y esto porque "Dios les otorga su primera misericordia" (EG 198). Los pobres tienen un sitio preferencial en el corazón de Dios (EG 197) y esta preferencia tiene consecuencias para la vida de los creyentes: ellos tienen mucho que enseñarnos - nos evangelizan -, conocen al Cristo sufriente en sus propios dolores y la nueva evangelización ha de ponerlos en el centro de su camino, reconociendo la fuerza salvífica de sus vidas (EG 198).

Los pobres para el Papa Francisco son los pobres reales, no los pobres "espirituales" como tantas veces se oye decir a aquellos que parecen huir de la radicalidad del evangelio. Los pobres son aquellos en los que hay que descubrir a Cristo y prestarles nuestra voz para sus causas, además de ser sus amigos, escucharlos, interpretarlos y recoger la misteriosa sabiduría que Dios quiere comunicarnos a través de ellos (EG 198). La auténtica opción por los pobres no utiliza a los pobres sino que los ama realmente y los acompaña adecuadamente en su camino de liberación (EG 199). Más aún, nadie puede sentirse exceptuado de la preocupación por los pobres y por la justicia social ni puede mantenerse lejos de los pobres argumentando que sus opciones de vida les implican prestar atención a otros asuntos. (EG 201). Los pobres también son "pueblo" y en ese sentido se ha de escuchar el clamor de pueblos enteros. Es tarea de todos crecer en solidaridad de manera que todos los pueblos puedan llegar a ser por sí mismos artífices de su destino (EG 190).

Estas afirmaciones fundamentan el querer del Papa frente a la Iglesia: "Quiero una Iglesia pobre y para los pobres" (EG 198) y no sólo por ser su propio deseo sino por la radicalidad de la encarnación de Jesús quien se hizo 
pobre y escogió un camino de salvación desde ellos, expresado en el texto programático de Lc 4, 18: "El Espíritu del Señor está sobre mí, porque me ha ungido. Me ha enviado para anunciar el Evangelio a los pobres" (EG 197).

Por esto, la evangelización encierra una dimensión social ineludible. En un contexto social donde crecen los movimientos religiosos de tipo más conservador, más preocupados por la ortodoxia que por la ortopraxis, la Exhortación sigue sorprendiendo al dedicar tanto espacio a la dimensión social de la Evangelización. No pretendemos decir que esta dimensión haya estado ausente de la preocupación eclesial. Basta remitirnos a la Doctrina Social de la Iglesia y a distintos planteamientos que la Iglesia ha hecho a lo largo de su historia sobre estos aspectos. Pero sí queremos resaltar que tal vez no se había hablado con tanta contundencia frente al sistema económico vigente desde instancias papales. En este sentido, no se hicieron esperar las críticas sobre este punto, tan pronto salió a la luz este documento ${ }^{12}$. Para referirse a esta dimensión social el papa aborda cuatro puntos: la repercusión social del kerygma, la inclusión de los pobres, el bien común y el diálogo para la construcción de la paz.

La labor misionera de la Iglesia comienza con el anuncio del kerygma. $\mathrm{Y}$ este anuncio tiene ineludiblemente una dimensión social porque "la vida comunitaria y el compromiso con los otros" son el corazón mismo del Evangelio (EG 177). De no hacerlo "se corre el riesgo de desfigurar el sentido auténtico e integral que tiene la misión evangelizadora" (EG 176). Los textos de la Sagrada Escritura así lo confirman: "Lo que hiciste a uno de estos hermanos míos más pequeños, a mí me lo hiciste” (Mt 25, 40) (EG 179).

Ahondando en esa dimensión social del Kerygma, el Papa, citando a Benedicto XVI, señala que aunque el orden justo de la sociedad y del Estado es tarea principal de la política, "la Iglesia ni puede ni debe quedar al margen en la lucha por la justicia"13 e insta a todos los cristianos, pero también a los Pastores, a preocuparse por la construcción de un mundo mejor (EG 183). Ahora bien, deja claro dos cosas: (1) la Iglesia ha de decir una palabra social - la Doctrina social de la Iglesia - (2) la Iglesia "no tiene el monopolio en la

\footnotetext{
${ }^{12}$ Rush Limbaugh, un locutor conservador de EEUU, criticó las declaraciones del pontífice sobre las desigualdades económicas en la Iglesia, acusándolo de estar predicando "puro marxismo". http://mexico.cnn.com/mundo/2013/12/02/el-papa-francisco-esta-predicando-puro-marxismo-dice-locutor-de-eu

${ }^{13}$ BENEDICTO XVI, P. P. Carta Encíclica Deus Caritas Est. Ciudad del Vaticano: Librería Editrice Vaticana, 2005. No. 28.
} 
interpretación de la realidad social o la propuesta de soluciones a los problemas contemporáneos" (EG 184). La tarea humana es de todos y la Iglesia ha de colaborar con otros, eso sí, ofreciendo su palabra con audacia y valentía, pero también con humildad y capacidad de aprender de los demás.

El Papa afirma que el sistema económico vigente es "exitista" y "privatista" e impide que los "lentos, débiles o menos dotados puedan abrirse camino en la vida" (EG 209). Las causas estructurales de la pobreza no se resuelven sin "renunciar a la autonomía absoluta de los mercados y a la especulación financiera y atacando las causas estructurales de la inequidad" (EG 202). Palabras como ética, solidaridad, distribución de bienes, etc., molestan al sistema imperante. No se puede confiar más en "la mano invisible del mercado" que sólo apunta a buscar crecimiento económico sin tomar en cuenta que se requiere algo más que esa libre competencia para crear programas y proyectos que defiendan a los más débiles (EG 204). Tal vez el Papa, adelantándose a las críticas, dice que no pretende ofender a nadie con sus palabras, ni mira a las personas gestoras de estas economías como enemigos, sino que desea que "aquellos que están esclavizados por una mentalidad individualista, indiferente y egoísta, puedan liberarse de esas cadenas indignas y alcancen un estilo de vida y de pensamiento más humano, más noble, más fecundo que dignifique su paso por esta tierra" (EG 208).

La crítica expresada en el documento no apunta solamente al mercado por el mercado sino a la dicotomía entre este y los sistemas políticos que no limitan los excesos de unos cuantos sobre los demás. Crece la cultura del consumismo y voracidad individualista y no hay preocupación por la cooperación y la inclusión de los débiles en la sociedad. De ahí que la "inclusión de los pobres" es uno de los desafíos actuales y a esto no puede ser ajena la comunidad eclesial: "Cualquier comunidad de la Iglesia, en la medida en que pretenda subsistir tranquila sin ocuparse creativamente y cooperar con eficiencia para que los pobres vivan con dignidad y para incluir a todos, también correrá el riesgo de la disolución, aunque hable de temas sociales o critique a los gobiernos. Fácilmente terminará sumida en la mundanidad espiritual, disimulada con prácticas religiosas, con reuniones infecundas o con discursos vacíos" (EG 207).

Para el Papa Francisco, hablar de paz no es mantener el status quo establecido, sino garantizar la vida digna para todos y todas. La paz va de la mano de una voz profética que vele por los derechos de los más desposeídos. La paz tampoco se reduce a ausencia de guerras. Supone la conformación de 
unos Estados donde sea posible la ciudadanía con el libre ejercicio de derechos y deberes (EG 218-220). Ve en el diálogo una mediación indiscutible para la construcción de la paz y la Iglesia está llamada a un diálogo sincero en procura del bien común. Es necesario establecer diálogo con los Estados, con la sociedad - que incluye el diálogo con las culturas y las ciencias - y con los otros creyentes que no forman parte de la iglesia católica (238). En estos diálogos, la iglesia ha de fomentar el encuentro y la búsqueda de consensos y acuerdos pero sin dejar de preocuparse por la sociedad justa, memoriosa y sin exclusiones (EG 239). La Iglesia sabe que no tiene soluciones para todas las cuestiones particulares pero ha de articularse con aquellas propuestas que mejor respondan a la dignidad de la persona humana y al bien común. La Iglesia propone valores fundamentales que pueden traducirse en acciones políticas (EG 241).

En su diálogo con las otras ciencias, la Iglesia no tiene miedo a la razón sino que busca y confía en ella "porque la luz de la razón y la de la fe provienen ambas de Dios" $"$. No hay porque dejar de lado los avances científicos sino discernirlos mostrando que una verdadera teoría científica no se contradice con la opción de fe (EG 243).

El diálogo ecuménico es una de las aristas en que hoy en día se juega más la credibilidad de las Iglesias. Pero ha de ser un diálogo sincero confiando en el compañero de camino "sin recelos, sin desconfianzas", buscando la paz en el rostro del único Dios (EG 244). No podemos agregar más divisiones a países ya de por sí disgregados por la violencia. Antes bien, esa unidad será un camino ineludible de evangelización en la medida que se acoja lo que el Espíritu ha suscitado en cada iglesia.

En esta tarea de unidad, no menos importancia cobra el diálogo interreligioso. Este diálogo no es simplemente tolerancia o relativismo sino apertura desde la propia identidad, capaces de mantenerse firme en las convicciones más hondas, pero dispuestos a entender y valorar las otras confesiones religiosas (EG 250-254).

Como ya se señaló al inicio, la Exhortación apunta a indicar los caminos para una nueva etapa evangelizadora, lo que permitirá la tan necesaria renovación eclesial. Esto no se puede hacer sin una profunda conversión pastoral ${ }^{15}$ y misionera (EG 25) que parta de redescubrir el Evangelio como fuente de Alegría y el encuentro con Jesús como una llamada a la misión que

\footnotetext{
${ }^{14}$ JUAN PABLO II, P. P. Carta Encíclica Fides et ratio. Tipografía Vaticana, 1998, No. 43.

${ }^{15}$ Como ya lo delineo la Conferencia de Aparecida 366. V Conferencia del Episcopado Latinoamericano y del caribe. Documento conclusivo. Bogotá: CELAM/San Pablo/Paulinas, 2007.
} 
es razón y sentido de la Iglesia (EG 1). Es claro que el Papa retoma el espíritu de la V Conferencia de Aparecida: "ser una Iglesia en permanente estado de Misión" (EG 25). Por tanto, la transformación que se necesita surge de una conversión al sueño misionero de llegar a todos, razón última de la comunidad eclesial (EG 31).

La primacía de la transformación eclesial que propone el Papa, la tiene el dinamismo del Espíritu que "es capaz de hacer nuevas todas las cosas" (AP 21,5). Y ese Espíritu llama a ser "una Iglesia en salida". De hecho ese es el título del numeral 1 del primer capítulo de la Exhortación. Allí el Papa acude a la historia de salvación con Abraham, Moisés y Jeremías para mostrar como en la Palabra de Dios aparece permanentemente ese dinamismo de "salida". Por eso la misión a la que Jesús llama implica "salir de la propia comodidad y atreverse a llegar a todas las periferias que necesitan la luz del Evangelio" (EG 20). No debe temer quedar accidentada, herida o manchada por salir a la calle, esto es preferible a ser una "iglesia enferma por el encierro y la comodidad de aferrarse a las propias seguridades" (EG 49). "La Iglesia debe aceptar esa libertad inaferrable de la Palabra, que es eficaz a su manera, y de formas muy diversas que suelen superar nuestras previsiones y romper nuestros esquemas" (EG 22). “¡Atrevámonos un poco más a ¡primerear!” Y se podría deducir de todo el párrafo, a "involucrarse", a "acompañar", a "fructificar", a "tener olor a oveja", a "festejar" (EG 24).

Para poder convertirse en una Iglesia en salida, en misión, consciente de su necesidad de perenne reforma (EG 26), se requiere una transformación de todo: "costumbres, estilos, horarios, lenguaje y toda estructura eclesial" para que se ponga al servicio de la evangelización del mundo actual más que para la autopreservación (EG 27). Se necesita dejar el cómodo criterio pastoral 'del siempre se ha hecho así' y atreverse a la creatividad y la audacia para repensar toda la pastoral (EG 33).

Y, explícitamente, el Papa dice que si todas las estructuras necesitan conversión y renovación, también el Papado ha de entrar en esa dinámica. La expresión "obispo de Roma” en lugar de Papa o Sumo Pontífice que el Papa ha usado desde el inicio de su Pontificado, también la utiliza aquí, reconociendo "que también el Obispo de Roma ha de estar abierto a las sugerencias que se orienten a un ejercicio de su ministerio que lo vuelva más fiel al sentido que Jesucristo quiso darle y a las necesidades actuales de la evangelización". En consonancia con la revisión del papel que juega el Obispo de Roma, retoma lo que ya fue dicho en el Vaticano II y que, en cierta medida, no ha podido 
desplegarse en la praxis eclesial. Se refiere al protagonismo que han de tener las Conferencias Episcopales siendo reconocidas como sujetos de atribuciones concretas, incluyendo también alguna auténtica autoridad doctrinal". En realidad el Papa está señalando la necesaria descentralización para una vivencia misionera más ágil y comprometida con cada realidad (32). Es de anotar que en el mismo texto el Papa comienza a valorar el aporte de las Conferencias al tomar a estas como referencias bibliográficas de la Exhortación ${ }^{16}$.

En este mismo sentido de participación, habla del Pueblo de Dios como "sujeto de evangelización" y por eso al referirse a cada uno de los miembros de la Iglesia reclama su protagonismo e implicación existencial. A los obispos les invita a ir "delante, con y detrás del pueblo" para prestar atención a lo que dice el "rebaño" porque este "tiene su olfato para encontrar nuevos caminos" (EG 31). En lo que respecta al laicado, que son la inmensa mayoría del Pueblo de Dios, han crecido en identidad y compromiso. Sin embargo falta asumir más su misión evangelizadora no sólo a nivel intraeclesial sino en el mundo social, político y económico. Reconoce que una de las causas del poco protagonismo laical es el fuerte clericalismo que aún persiste (EG 102). Sobre la mujer el Papa es consciente de la necesidad de "ampliar los espacios para una presencia femenina más incisiva en la Iglesia (...) y en los diversos lugares donde se toman las decisiones importantes, tanto en la Iglesia como en las estructuras sociales" (EG 103).

La importancia de la Iglesia como "Pueblo de Dios" es también central y supone recuperar esa expresión tan decisiva del Vaticano $\mathrm{II}^{17}$ que desde hace años había sido opacada por eclesiologías verticalistas. La importancia del "Pueblo" es uno de los grandes aportes del texto, y es fundamental para la eclesiología latinoamericana. Dios ha elegido "convocarnos como Pueblo y no como seres aislados" (EG 113). "Ser Iglesia es ser Pueblo de Dios" (EG 114). "Este Pueblo de Dios se encarna en los pueblos de la tierra, cada uno de los cuales tiene su propia cultura" (EG 115). Y en este sentido también es de celebrar la importancia que da a lo largo del texto a la religiosidad popular:

\footnotetext{
${ }^{16}$ Ecclesia in África (nota 57, 92) ; Ecclesia in Asia (nota 58, 77, 78, 95, 99, 134); Ecclesia in América (nota 149), Ecclesia in Oceanía (nota 91, 94); Ecclesia in Medio Oriente (nota 203); Conferencia de Obispos de Brasil (nota 158); Conferencia de Obispos de Congo (nota 184); Conferencia de Obispos de Filipinas (nota 176); Conferencia de Obispos de Francia (nota 60, 174); Conferencia de Obispos de India (nota 194); Conferencia de Obispos católicos de Estados Unidos (nota 59, 180); II Asamblea especial para Europa del Sínodo de Obispos (nota 211).

${ }^{17}$ Precisamente la categoría "Pueblo de Dios" fue decisiva en la estructuración de la Constitución dogmática Lumen Gentium (Capítulo 2).
} 
"verdadera expresión de la acción misionera espontánea del Pueblo de Dios. Se trata de una realidad en permanente desarrollo, donde el Espíritu Santo es el agente principal" (EG 122).

La renovación eclesial supone también mirar el contenido de una pastoral misionera. Esta "no se obsesiona por la transmisión desarticulada de una multitud de doctrinas que se intenta imponer a fuerza de insistencia (...) se concentra en lo esencial (...) así se vuelve más contundente y radiante (EG 35). Además hay que tener presente el orden o jerarquía de verdades - vale para los dogmas y toda la doctrina, incluso la enseñanza moral - (EG 36), que ayuda a discernir lo esencial de lo secundario y a buscar nuevas maneras de anunciar aquellas verdades ciertas pero que ya no dicen nada a los contemporáneos. Hay que recordar que "la expresión de la verdad puede ser multiforme, y la renovación de la formas de expresión se hace necesaria para transmitir al hombre de hoy el mensaje evangélico en su inmutable significado" (EG 41). No se puede perder de vista la adecuada proporción de aquello que se anuncia: "no se puede hablar más de la ley que de la gracia, más de la Iglesia que de Jesucristo, más del Papa que de la Palabra de Dios" (EG 38).

La inculturación del evangelio es una necesidad sentida, porque el "cristianismo no tiene un único modo cultural, sino que permaneciendo plenamente uno mismo (...) llevará consigo también el rostro de tantas culturas y de tantos pueblos en que ha sido acogido y arraigado" (EG 116). La diversidad cultural no amenaza la unidad de la Iglesia (EG 117), por el contrario, la multiplicidad de culturas enriquece a la Iglesia como "la novia que se adorna con sus joyas" (Cfr. Is 61,10) (EG 116).

$\mathrm{Y}$ en esta renovación eclesial el Papa es explícito al nombrar algunas actitudes y propuestas metodológicas concretas que deben adaptarse. Respecto a las actitudes, los agentes de pastoral han de abrirse al desafío de una espiritualidad misionera (EG 78-80), dejando toda acedía egoísta y todo pesimismo estéril (EG 81-86). El encuentro con Jesús los ha de llevar al compromiso con los hermanos (EG 87-92), librándoles de la mundanidad espiritual (EG 93-97) y de las envidias que surgen entre los mismos evangelizadores (EG 98-101). Reconociendo los desafíos pendientes con relación a la mujer, al laicado, a los jóvenes y al surgimiento de vocaciones, debe primar, por encima de todo, la alegría y la esperanza. El realismo de los hechos no puede quitar a los agentes de pastoral la fuerza misionera (EG 102-109). Sobre las propuestas metodológicas, el Papa se detiene en las estrategias misioneras que van del diálogo persona a persona hasta la novedad 
radical con que debe preparase la catequesis, la predicación y, por supuesto, la homilía. En todo debe primar el anuncio del Kerygma, la centralidad de la Palabra de Dios y el acompañamiento personal en todos los procesos de evangelización. Sin duda la parte que corresponde a la homilía es de suma importancia para un clero que no se prepara suficientemente, que no se renueva en su ministerio y no se actualiza constantemente para responder a las necesidades de sus destinatarios (EG 127-175).

\section{Conclusión}

Como hemos intentado señalar a lo largo de este escrito, los nuevos caminos para la evangelización suponen no sólo planes de acción sino modelos eclesiales que la respalden porque, como ya dijimos, la Iglesia no tiene una misión, ella es misión y su mismo ser y estar en el mundo se convierte en la primera palabra que evangeliza, en el signo visible que puede convocar al seguimiento de Jesucristo. Por tanto, la llamada a la conversión eclesial, pastoral y misionera son tres aspectos de una misma realidad: la llamada a revisar el modelo eclesial que encarnamos en este presente para renovarlo, orientarlo, dinamizarlo, hacerlo converger, cada vez más, con un modelo eclesial que pueda transparentar mejor la Buena Noticia del Reino.

De todo lo señalado ¿podríamos hacer un resumen que nos haga más fácil el camino a seguir? Posiblemente podríamos enfatizar tres aspectos, inspirados en el modelo trinitario: convirtámonos a una Iglesia con el amor misericordioso del Dios Padre-madre, con la pasión por los pobres vivida por Jesús en su anuncio del Reino, animados y fortalecidos por el Espíritu que con su libertad "hace nuevas todas las cosas" (Ap 21,5). En otras palabras, una Iglesia misericordiosa, una Iglesia pobre y para los pobres, una Iglesia libre $y$, por tanto, capaz de estrenar nuevos caminos que salgan al encuentro de los desafíos actuales.

Una primavera eclesial, una primavera evangelizadora será posible en la medida que seamos fieles al soplo del Espíritu que hoy sin duda pasa por la desinstalación, el riesgo, la creatividad, la audacia. Pero sobre todo pasa por "volver los ojos al Jesús del reino" para ponernos en camino con Él, al lado de los pobres, en un discipulado misionero capaz de abrir caminos de vida para todos y todas. 


\section{Referencias Bibliográficas}

ALBARRACÍN, T. "Perspectivas de la reforma litúrgica". Revista Theologica Xaveriana 149 (2003), pp. 513-521.

BENEDICTO XVI, P. P. Carta Encíclica Deus Caritas Est. Ciudad del Vaticano: Librería Editrice Vaticana, 2005.

CODINA, V. “Del Vaticano II... a ¿Jerusalén II?”. Revista Alternativas 41 (2011), pp. 65-74.

CODINA, V. Sentirse Iglesia en el invierno eclesial. Barcelona: Cuadernos Cristianisme e Justícia, 2006.

CODINA, ZUBIRÍA, COMBLIN, BALDUINO. “A 50 años del Vaticano II: verdaderas luces y urgentes desafíos”. Revista Alternativas 41 (2011).

Documentos completos del Vaticano II. Bilbao: El Mensajero, 1966.

FRANCISCO, P. P. Exhortación Apostólica Evangelii Gaudium. La alegría del Evangelio. Tipografía Vaticana, 2013.

IRIARTE, G. "Bodas de Oro del Vaticano II", In: PONENTES "Semana Teológica - Amerindia". A los 50 años del Concilio Vaticano II. Compendio de Ponencias presentadas en la "Semana Teológica". Cochabamba: Grupo Editoral "Kipus", 2011, pp. 33-48. Disponible en: http://amerindiaenlared.org/noticia/176/a-los-50-anos-del-conciliovaticano-ii/. Consultado el 12 de Octubre de 2014.

JUAN PABLO II, P. P. Carta Encíclica Fides et ratio. Tipografía Vaticana, 1998.

MADERA, I. "Una mirada irreversible". Revista Theologica Xaveriana 149 (2003), pp. 459-472.

VÉLEZ, C. "A 50 años del Vaticano II: verdaderas luces y urgentes desafíos". Revista Alternativas 41 (2011), pp. 89-100.

II Conferencia General del Episcopado Latinoamericano (MEDELLÍN). La Iglesia en la actual transformación de América Latina a la luz del Concilio. Bogotá: CELAM/San Pablo/Paulinas, 2014.

III Conferencia General del Episcopado Latinoamericano (PUEBLA). La Evangelización en el presente y en el futuro de América Latina. Bogotá: CELAM/San Pablo/Paulinas, 2014. 
IVConferencia General delEpiscopado Latinoamericano (SANTO DOMINGO). Nueva evangelización. Promoción humana. Cultura cristiana. Bogotá: CELAM/San Pablo/Paulinas, 2014.

V Conferencia del Episcopado Latinoamericano y del caribe (APARECIDA). Documento conclusivo. Bogotá: CELAM/San Pablo/Paulinas, 2007.

\section{Olga Consuelo Vélez Caro}

Doctora en Teología por la Pontificia Universidad Católica de Rio de Janeiro (Brasil)

Profesora Titular e Investigadora de la Facultad de Teología de la Pontificia Universidad Javeriana, Bogotá Bogotá - Colombia E-mail: ocvelez@javeriana.edu.co

Recebido em: 12/11/14 Aprovado em: 15/12/14 